DOCTRINA

\title{
El principio constitucional de inexcusabilidad resolutiva
}

\author{
The constitutional principle of decisive inexcusability
}

\author{
Lautaro Ríos Álvarez \\ Universidad de Valparaíso de Chile
}

\begin{abstract}
RESUMEN Es un principio fundamental en el ejercicio de una potestad aquel sin cuya presencia esta deja de funcionar. En mi opinión, son principios fundamentales en el ejercicio de la potestad jurisdiccional, la juridicidad, la congruencia y la inexcusabilidad resolutiva. La ausencia de cualquiera de ellas en el conocimiento y resolución de un asunto jurisdiccional le deja privado de valor y de eficacia. En esta reflexión abordaremos este último principio, no solo por su importancia decisiva para resolver efectivamente un asunto judicial, sino también por la trascendencia que le ha reconocido el sistema político chileno al otorgarle rango constitucional. La inexcusabilidad resolutiva consiste en la obligación que la Constitución impone al juez de decidir derechamente el conflicto o asunto que, siendo de su competencia, le ha sido sometido, debiendo resolverlo conforme a las leyes que lo regulan y, en su ausencia, de acuerdo con las demás fuentes jurídicas aplicables.
\end{abstract}

PALABRAS CLAVE Inexcusabilidad, resolutiva, constitucional.

ABSTRACT It is a fundamental principle in the exercise of a power, that without whose presence it ceases to function. In my opinion, they are fundamental principles in the exercise of the jurisdictional power, the legality, the congruence and the decisive inexcusability. The absence of any of them in the knowledge and resolution of a jurisdictional issue leaves him deprived of value and effectiveness. In this reflection we will address this last principle, not only because of its decisive importance to effectively solve a judicial issue, but also because of the importance that the Chilean political system has recognized in granting it constitutional rank. The decisive inexcusability consists of the obligation that the Constitution imposes on the judge to decide directly the conflict or issue that, being of its competence, has been submitted to it, having to resolve it according to the laws that regulate it and, in its absence, according to the other applicable legal sources.

KEYWORDS Inexcusability, resolutive, constitutional. 


\section{Origen normativo y definición}

Dos conceptos opuestos tienen relación directa con la inexcusabilidad. El primero es su versión afirmativa: «excusable» (del latín excusabilis), que significa «que se puede omitir o evitar». El segundo es su acepción negativa: «inexcusable» (del latín inexcusabilis), que quiere decir «que no puede eludirse con pretextos o que no puede dejar de hacerse».

Para nosotros, la inexcusabilidad resolutiva (Código Civil de la República de Chile, 1857: artículo 8; Corral Talciani, 1987) ${ }^{1}$ es un principio fundamental en el correcto ejercicio de la potestad jurisdiccional. Consideramos un principio fundamental de cualquiera función o potestad aquel sin cuya presencia estas dejan de funcionar válidamente. Y creemos, además, que son principios fundamentales en el ejercicio de la potestad jurisdiccional, la juridicidad (que algunos limitan impropiamente a la legalidad), la congruencia (Ríos Álvarez, 2015: 259 y ss.) ${ }^{2}$ y la inexcusabilidad resolutiva. La ausencia de cualquiera de ellas en el conocimiento y resolución de un asunto jurisdiccional, le deja privado de valor y de eficacia jurídica.

Entendemos por juridicidad la fiel sujeción del sentenciador al orden jurídico vigente a partir de la Constitución Política respectiva. La congruencia, siguiendo a Guasp:

Puede ser definida como la conformidad que debe existir entre la sentencia y la pretensión o pretensiones que constituyen el objeto del proceso, más la oposición u oposiciones en cuanto delimitan este objeto. Es, pues, una relación entre dos términos, uno de los cuales es la sentencia misma, y, más concretamente, su fallo o parte dispositiva, y otro el objeto procesal en sentido riguroso; no, por lo tanto, la demanda, ni las cuestiones, ni el debate, ni las alegaciones y las pruebas, sino la pretensión procesal y la oposición a la misma en cuanto la delimita o acota, teniendo en cuenta todos los elementos individualizadores del tal objeto: los sujetos que en él figuran, la materia sobre que recae y el título que jurídicamente lo perfila (Guasp, 1961: 533).

Por inexcusabilidad resolutiva entendemos la obligación del juez de resolver derechamente el conflicto judicial que -siendo materia de su competencia- ha sido sometido a su decisión, debiendo hacerlo conforme a las normas que lo regulan y, en su ausencia, de acuerdo con las demás fuentes de derecho disponibles.

El principio de juridicidad está consagrado en el artículo 6 de la Carta Fundamental de 1980 y es acotado en el artículo 7 . El principio de inexcusabilidad resolutiva lo establece el artículo 76 inciso 2 de la Constitución, por lo que ambos están revestidos de rango constitucional. El principio de congruencia se desprende del artículo 19 número 3 inciso 5 de la misma Constitución, y está contemplado en los artículos 160 y 170 del Código de Procedimiento Civil de Chile y por otras disposiciones de este Código que

1. Usamos el adjetivo «resolutiva» para distinguir esta inexcusabilidad de la de carácter cognitivo o inexcusabilidad por ignorancia de la ley, a la que se remiten el artículo y obra citadas.

2. Al Principio de Congruencia dedicamos un estudio, acá citado, en la obra colectiva Poder Judicial, cuyo detalle se encuentra en la sección referencias al final de este artículo. 
aseguran su vigencia y aplicación, habiendo sido calificado por la Excelentísima Corte Suprema como "principio rector de la actividad jurisdiccional».

En los orígenes de nuestra organización republicana -y en lo tocante al tema de este estudio-, destaca el título XII «Del Poder Judicial» de la Constitución Política de 1823, del cual prescribía que «todo juez responde de las dilaciones y abusos de las formas judiciales» (Constitución Política y Permanente del Estado de Chile, 1823: título XII, artículo 121).

Más específicamente, la Ley de 25 de septiembre de 1837, sobre Denegación de Justicia, disponía que:

El juez que en las causas cuyo conocimiento le compitiere se negare a administrar justicia: (seguía la enumeración de diversas actuaciones reprobables que culminaban con la siguiente -paréntesis nuestro-) Ya sea pretestando cualquiera otro motivo falso o manifiestamente frívolo que indique un ánimo deliberado de escusarse de tomar conocimiento de la causa. Comete crimen de denegación de justicia (Ley de Denegación de Justicia, 1837: artículo 1).

El Decreto Supremo referido acusa la influencia expansiva del Código Civil francés, el cual prescribe que «el juez que rehúse juzgar bajo pretexto del silencio, de la oscuridad o de la insuficiencia de la ley, podrá ser perseguido como culpable de denegación de justicia» (Código Civil de Francia, 1804: artículo 4; Martínez Benavides, 2012: 113 y ss.)

En 1847, se presentó a la Cámara de Diputados, por don Antonio Varas, un proyecto de ley acerca del modo de acordar y fundar las sentencias definitivas. Consultado el autor de nuestro Código Civil, don Andrés Bello, propuso la siguiente disposición.

Toda sentencia [...] contendrá:

3. Los hechos y las disposiciones legales, en defecto de estas, la costumbre que tenga fuerza de ley; y a falta de unas y otras, las razones de equidad natural que sirvan de fundamento a la sentencia (Ley de Modo de Acordar y Fundar las Sentencias, 1851: artículo 3).

Esta ley se promulgó el 12 de septiembre de 1851 (Fernández González, 2014: 41 y ss.)

En el ordenamiento jurídico chileno posterior, la primera norma legal codificada que estableció la inexcusabilidad del juez fue la Ley de Organización y Atribuciones de los Tribunales de 1875 , que prescribía que:

Reclamada su intervención en forma legal y en negocios de su competencia, [los tribunales] no podrán excusarse de ejercer su autoridad ni aun por falta de ley que resuelva la contienda sometida a su decisión (Ley de Organización y Atribuciones de los Tribunales, 1875: artículo 9, inciso segundo).

El texto de esta norma se reprodujo idéntico al original de 1875 en el Código Orgánico de Tribunales (1943: artículo 10, párrafo segundo). Además, el mismo Código dispuso que: 
Siempre que según la ley fueren competentes para conocer de un mismo asunto dos o más tribunales, ninguno de ellos podrá excusarse del conocimiento bajo el pretexto de haber otros tribunales que puedan conocer del mismo asunto; pero el que haya prevenido en el conocimiento excluye a los demás, los cuales cesan desde entonces de ser competentes (Código Orgánico de Tribunales de Chile, 1943: artículo 112).

Cabe advertir, sin embargo, que esta no es una novedad del Código Orgánico de Tribunales, sino la reproducción de lo previamente dispuesto en el original de 1875 (Ley de Organización y Atribuciones de los Tribunales, 1875: artículo 196).

Fue la Constitución Política de 1980 la que elevó el deber de inexcusabilidad al supremo rango normativo (Constitución Política de la República de Chile, 1980: artículo 73 , segundo párrafo), ${ }^{3}$ cuyo texto reproduce el contenido de la disposición transcrita de la Ley Orgánica de 1875, añadiendo sabiamente a la expresión «contienda» la más extensiva: «o asunto», que perfecciona su alcance.

Decimos que la expresión agregada es sabia y extensiva porque frente al texto dispuesto en el Código Orgánico de Tribunales (1943: artículo 10) y tratándose de un asunto incidental o de un trámite procesal, el juez podía eludir su pronunciamiento fundándose en que la cuestión suscitada no afectaba la decisión de «la contienda» misma. Al añadir el vocablo omnicomprensivo «o asunto», se clausura esta vía de escapatoria y se obliga al tribunal a pronunciarse en todo caso.

El texto de la disposición constitucional aludida reza que «reclamada su intervención en forma legal y en negocios de su competencia, [los tribunales] no podrán excusarse de ejercer su autoridad, ni aún por falta de ley que resuelva la contienda o asunto sometidos a su decisión» (Constitución Política de la República de Chile, 1980: artículo 76, inciso segundo).

La inexcusabilidad puede definirse -en nuestro sistema jurídico- como la obligación que la Constitución Política de la República y el Código Orgánico de Tribunales imponen expresamente a todo juez de resolver el asunto legalmente sometido a su decisión que la ley haya puesto dentro de la esfera de su competencia, debiendo hacerlo en conformidad con las leyes que lo regulan y, a falta de ellas, de acuerdo con las demás fuentes jurídicas aplicables.

\section{Fundamento jurídico-político}

El profesor Hugo Pereira Anabalón menciona que:

El Estado detenta el poder público de mandar y de ser obedecido por aquellos a quienes el mandato se dirige; pero la legitimidad del poder público exige el consentimiento de estos. Por ello, en el artículo 21.3, la Declaración Universal de los Derechos Humanos expresa que «la voluntad del pueblo es la base de la autoridad del poder público».

3. Actualmente se encuentra vigente como Constitución Política de la República de Chile de 1980, artículo 76 , inciso segundo. 
La potestad jurisdiccional no escapa a tal postulado, de donde el fundamento de la misma es precisamente la voluntad popular, o la soberanía popular, o simplemente la soberanía. Por tanto, los titulares de la jurisdicción, los jueces, la ejercitan en representación del pueblo, del soberano.

Nuestra Constitución [...] expresa que la soberanía reside en la nación y que su ejercicio se realiza por el pueblo y por las autoridades que la Carta establece (artículo 5, inciso 1), entre estas, por cierto, la autoridad judicial [Poder Judicial] que regula su capítulo VI, al cual asigna la potestad jurisdiccional (Pereira Anabalón, 1993: 93).

La Excelentísima Corte Suprema, en sentencia de 6 de mayo de 1964, estableció que:

En el artículo 8o de la Carta Fundamental (actual artículo 76) descansa la función jurisdiccional de los tribunales, la que es una emanación de la soberanía del Estado; y asegura asimismo la independencia de aquellos para juzgar las controversias, etcétera (Revista de Derecho y Jurisprudencia, 1964: tomo 61, 81).

La misma Corte, en sentencia de 3 de mayo de 1965, declaró que «el poder público en que la soberanía ha delegado la función de administrar justicia tiene la facultad de hacer ejecutar lo juzgado, usando la fuerza si ello es necesario (Revista de Derecho y Jurisprudencia, 1965: tomo 62, 60).

\section{Trascendencia del principio de inexcusabilidad}

La trascendencia de este principio fundamental del ejercicio de la jurisdicción no solo deriva de haber sido positivado en una disposición de supremo rango normativo como lo es una norma de rango constitucional (Constitución Política de la República de Chile, 1980: artículo 76), que es cabeza de su capítulo VI que regula el «Poder Judicial». Deriva, más bien, de la esencialidad de su aplicación, ya que su ausencia o su infracción corrompería el deber del Estado de impartir justicia y la necesidad imperiosa de recibirla con prontitud por los afectados.

El Poder Ejecutivo y la administración del Estado pueden abstenerse, en determinados casos -sea por razones de mérito, de oportunidad o de conveniencia- de adoptar medidas de gobierno o de administración. Puede hacerlo inclusive ante situaciones de excepción sin infringir la Constitución.

El Congreso Nacional puede hacer lo mismo, en todo cuanto concierne a la aprobación, modificación o rechazo de los proyectos de ley que reciba por mensajes del Ejecutivo o por mociones de los propios congresales.

Tanto el Gobierno y la administración como el Congreso Nacional tienen opciones para actuar o para abstenerse de actuar, y el que termina decidiendo acerca del acierto o el desacierto de esas opciones es el cuerpo electoral.

En cambio, los tribunales de justicia, ante el asunto de su competencia que legalmente se somete a su decisión, carecen de la opción de resolverlo o de abstenerse de hacerlo. Deben ejercer su autoridad sin poder excusarse ni siquiera por falta de ley que resuelva el asunto sometido a su decisión. 
Una sociedad puede vivir en ausencia de leyes que no necesite; puede sobrevivir agobiada por una burocracia frondosa que frene su capacidad de emprendimiento; o bajo gobiernos que a veces omitan o no entiendan debidamente las necesidades de seguridad y de vivir en paz de la población. Pero no puede subsistir desprovista de justicia ni angustiada por la tardanza injustificada en recibirla.

Por otra parte, la administración de justicia -salvo el escaso poder de la opinión pública- no cae bajo el control del cuerpo electoral y es mejor que así sea.

Pero esta falta de control externo y la trascendencia de su noble misión debiera interpelar la conciencia de los jueces para decidir los asuntos que se les someten de manera pronta y clara, y con la mirada puesta más en la justicia del caso que en la multitud de detalles que a veces nublan la fisonomía del problema entregado a su decisión.

\section{Requisitos de procedencia de la inexcusabilidad}

De acuerdo con su definición y al texto constitucional que lo establece, el deber de inexcusabilidad de todo tribunal de justicia depende de la conjunción de los siguientes requisitos:

- Requerimiento judicial de la persona natural o jurídica habilitada para comparecer en juicio.

- Que dicho requerimiento se practique en conformidad a la ley procesal correspondiente a su materia.

- Que el asunto propio del requerimiento esté comprendido dentro de la competencia del tribunal requerido (Código Civil de la República de Chile, 1857: artículos 19 a 24; Código de Procedimiento Civil de Chile, 1902: artículo 170, número 5$).^{4}$

\section{Precedentes históricos del deber de inexcusabilidad}

Aunque pareciera que la acuñación legislativa de esta obligación recién debió ver la luz a raíz de los procesos de codificación de las normas legales -esto es, a partir del comienzo del siglo XIX- existen precedentes históricos que desvirtúan esta suposición (Topasio Ferreti, 1983: 155-164; Figueroa Quinteros, 1996: 187-196). ${ }^{5}$

Así, desde la Alta Edad Media empieza a perfilarse el sistema de legalismo jurídico que obligaba a los jueces a sentenciar en conformidad a las leyes vigentes, desechando la aplicación de la legislación de Roma e inclusive de las opiniones de los grandes jurisconsultos romanos (Ulpiano, Papiniano, Paulo, Modestino y Gayo).

Esta obligación se consagraba en el «Liber Iudiciorum»o Libro de los jueces del

4. Ver las reglas sobre «Interpretación de la ley» del Código Civil citados, el cual, al igual que la norma referida del Código de Procedimiento Civil de 1903, hacen referencia a otras fuentes jurídicas.

5. En esta incursión histórica nos hemos basado en el trabajo de los profesores de Historia del Derecho acá citados. 
año 654 de nuestra era, compendio de las tres ediciones de la legislación civil visigoda que imponía a los jueces la obligación de aplicar los principios y normas contenidas en dicha normativa. Así, el libro II, cuyo título I se denomina «De los jueces y de lo que juzgan», expresaba en su Ley VIII:

Bien sufrimos y bien queremos que cada hombre sepa las leyes de los extraños para sí; pero cuando se trata de juzgar pleitos, defendémoslo y contradecimos que no las usen [...] porque abundan para hacer justicia las razones y las palabras y las leyes que son contenidas en este libro. Ni queremos que en adelante sean usadas las leyes romanas ni las extrañas (Liber Iudiciorum, 654: libro II, título I, Ley VIII).

La Ley IX del mismo Libro de los jueces prescribía:

Ningún hombre de todo nuestro reino defendemos que no presente al juez para juzgar en ningún pleito otro libro de leyes sino este nuestro... Y si lo hiciere alguno, peche 30 libras de oro al rey. Y si el juez tomara el otro libro defendido, si no lo rompiere o no lo despedazare, reciba aquella misma pena (Liber Iudiciorum, 654: libro II, título I, Ley IX).

La Ley XI, por su parte, disponía qué ha de hacer el juez cuando no hay ley que decida el caso, ordenando que:

El señor de la ciudad, o el juez por sí mismo, o por su encargado haga presentar ambas las partes ante el rey para que el pleito sea tratado ante él («que pleyto sea tratado antel») y sea terminado así sin más, y que se haga entonces ley (Liber Iudiciorum, 654: libro II, título I, Ley XI).

La Ley XII agregaba que «los príncipes tienen poder de añadir leyes en este libro todavía, y los pleitos que ya están iniciados y no están aún terminados, mandamos que sean terminados según estas leyes» (Liber Iudiciorum, 654: libro II, título I, Ley XII).

La imposición de este temprano legalismo la explica el profesor Alamiro de Ávila y señala que «la política de los reyes en esta materia es, fundamentalmente, la de imponer un sistema de derecho que contribuya a aumentar el poder de la monarquía» (Ávila Martel, 1995: 219). ${ }^{6}$

El profesor Topasio concluye y señala que «en conformidad a los preceptos del Libro de los jueces, a falta de ley que resuelva el caso sometido a su decisión, el juez debe excusarse de pronunciar la propia decisión y deferir el asunto al rey para que este lo defina» (Topasio Ferreti, 1983: 157).

Sin embargo, no debe olvidarse que durante la Edad Media la potestad de hacer justicia estaba radicada en el monarca, de quien el juez era un simple delegatario de esa potestad que se ejercía en su nombre. De allí que la «excusa» del juez solo significaba que, a falta de ley aplicable al caso, este reenviaba el asunto al poder concentrado del rey quien no solo era el titular de la potestad judicial, sino también de la potestad legis-

6. Citado por el profesor Aldo Topasio. 
lativa, por lo que podía subsanar el vacío legal y a continuación, resolver el asunto en conformidad a la nueva norma creada por él mismo. Quiero decir que -en mi modesta opinión- el deber de inexcusabilidad de hacer justicia continuaba vigente si resolvía el Rey.

La profesora María Angélica Figueroa menciona que:

Especial relevancia tiene al final del período altomedieval la dictación por las primeras Cortes del reino de León de los decretos aprobados por esta asamblea legislativa triestamental el año 1188, conocidos más tarde como «Carta Magna leonesa» por asimilación comparativa con la Carta Magna inglesa de 1215. Dicho texto, que rigió como derecho para todo reino, contiene en su mayoría, normas de tipo procesal. Entre ellas dispone que la denegación o retardo malicioso en la administración de justicia por parte del juez -y la carta leonesa entiende que existe retardo si «hasta el tercer día no se aplicara el derecho»- faculta al agraviado por la denegación o retardo para exigir del juez, una vez probado el hecho mediante testigos «pagar dobladas al querellante, tanto la cuantía de la demanda como los gastos» (Figueroa Quinteros, 1996:192-193).

Durante la baja Edad Media -en lo que respecta al principio en estudio- merece citarse el Código de las Siete Partidas del Rey Alfonso X, el Sabio, y el Fuero Real de España, otorgado por el mismo Rey, ambos en el siglo XIII, los que resultan ser la continuidad del antiguo Libro de los jueces del siglo VII.

En la partida III, título XXII, su Ley XI, se refería a «qué deben hacer los juzgadores cuando dudaren, y cómo deben dar su juicio»; allí aparecía la siguiente minuciosa instrucción:

[Los jueces] deben hacer escribir todo el pleito, como pasó ante ellos, bien y lealmente, y después hacerlo leer ante las partes, para que vean y entiendan si está escrito todo lo que fue razonado. Y si hallaren que alguna cosa está crecida o menguada o cambiada, débenla enderezar, y después sellar el escrito con sus sellos, y dar a cada una de las partes el suyo, para que lo lleven al Rey; y sobre todo esto deben los jueces hacer su carta, y enviarla al Rey, recontándole todo lo hecho, y la duda en que están. Y entonces el Rey, sabida la verdad, puede dar el juicio, o enviar decir a aquellos juzgadores, como lo den, si se quisiere (Siete Partidas, 1265: partida III, título XXII, Ley XI).

Y en el título XXVIII del Ordenamiento de Alcalá de Henares, titulado «Por qué leyes se pueden librar los pleitos», previendo qué debe hacerse en defecto de ley, Alfonso XI dispuso:

Y si alguna contrariedad apareciere en las leyes sobredichas entre sí mismas, o en los fueros, o en cualquiera de ellos, o alguna duda fuere hallada en ellos, o algún hecho porque por ellos no se puede librar [el pleito], que nosotros seamos requeridos sobre ellos, para que hagamos interpretación, o declaración o enmienda, y hagamos ley nueva, la que entendiéremos que cumple sobre ello, para que la justicia y el derecho sean guardados. (Ordenamiento de Alcalá de Henares, 1348: título XXVIII) 
Por su parte, el Fuero Real de España del año 1255, en su libro I, título VI, Ley V, expresaba lo siguiente:

Bien sufrimos e queremos que todo home sepa otras leyes por ser más entendidos los homes, é más sabidores: mas no queremos, que ninguno por ellas razone, ni juzgue: mas todos los pleytos sean juzgados por las leyes de este libro, que nos damos a nuestro pueblo, que mandamos guardar: é si alguno aduxere otro libro de otras leyes en juicio para razonar, ó para juzgar por él, peche quinientos sueldos al Rey: pero si alguno razonare ley que acuerde con la deste libro, é las ayude, puede lo hacer, é no haya pena (Fuero Real de España, 1255: libro I, título VI, Ley V; Topasio Ferreti, 1983: 157, nota 4).

El profesor Topasio señala que desde la época de los Reyes Católicos en adelante el principio de inexcusabilidad de la justicia mantendría su vigencia, al menos en la legislación del Imperio español y de sus colonias. Así, la Pragmática de Madrid de 1499, que permitió excepcionalmente, a falta de ley, la invocación en juicio de las opiniones de los jurisconsultos Bartolo, Baldo, Juan Andrés y del Abad Panormitano, fue derogada por la Ley Primera de Toro, la que restaura, a falta de ley aplicable, la abstención del juez y el envío de todos los antecedentes al Rey para llenar el vacío legal y resolver el asunto en conformidad con la nueva ley que este dicte.

La reina doña Isabel, por Real Cédula de 29 de marzo de 1503 expedida en Alcalá de Henares -en caso de duda insuperable del sentido de la ley- dispone:

Si por ventura algún pleito fuere tan dudoso e intrincado, que parece que no se puede determinar bien la justicia, y que se debe mandar comprometer, los dichos presidente y oidores no lo hagan, sin consultarlo primero con nos, y nos envíen la razón del negocio que fuere, con los votos de los oidores que lo hubieren visto y con las causas que les movieren, para que nos mandemos lo que se debe hacer (Novísima Recopilación de las Leyes de España, 1805: Ley VII, libro V, título I).

El principio de inexcusabilidad se mantendrá incólume tanto en la Nueva Recopilación de Leyes de Castilla como en la Novísima Recopilación de las Leyes de España (Nueva Recopilación de Leyes de Castilla, 1567: libro II, título I, leyes III y VII; título V, Ley XIII; Novísima Recopilación de las Leyes de España, 1805: libro III, título II, leyes III y VII; Topasio Ferreti, 1983: 161, nota 11).

Con respecto al derecho aplicable en las colonias españolas, la profesora María Angélica Figueroa destaca lo siguiente:

Pasemos finalmente al derecho indiano, el que como sabemos, fue creado como un derecho particular para América, el cual en los amplios vacíos con respecto a materias no reguladas de modo especial, como derecho penal, civil, procesal, debía ser suplido por el derecho castellano de acuerdo con el orden de prelación de las Leyes de Toro. Este, sabemos, cerraba la creación de derecho en torno al rey de modo expreso, con las salvedades que ya hemos advertido sobre la supremacía del derecho natural.

Solo la vigencia del derecho positivo indiano castellano supeditado al contenido de un concepto valorativo de derecho natural puede explicarnos funciones como las de 
las audiencias americanas con respecto a la «suplicación de la ley injusta» frente a la cual la audiencia dejaba a salvo el reconocimiento de la legitimidad de la potestad real para legislar mediante el «acatamiento» de la ley, pero se hallaba obligada a suspender la aplicación de la ley y a «suplicarla» en los casos en que su contenido fuera «injusto». Como sabemos, en la práctica el mecanismo se utilizó correcta e incorrectamente, en nuestro análisis interesa en la medida que es una comprobación de la apertura del sistema hacia la equidad. Solo del mismo modo es posible explicar la adaptación al tiempo, al lugar y a las circunstancias que se dio a las Partidas en América según nos testimonia la jurisprudencia indiana en la medida en que se ha ido trabajando sobre ella. Creemos que en América indiana imperó un sistema de arbitrio judicial que con diversos controles tendientes a evitar la arbitrariedad permitió a los jueces hacer prevalecer, sobre el texto positivo que resolviera el caso, la formulación de fallos basados en la equidad. El juez no estaba obligado a fundamentar de modo expreso su sentencia (Figueroa Quinteros, 1996: 194).

Cabe señalar que, concluida la reconquista, la Constitución de 1818 ratificó la vigencia de «las leyes, cédulas y pragmáticas que hasta aquí han regido a excepción de las que pugnan con el actual sistema liberal de gobierno. En este caso consultarán con el Senado, que proveerá remedio» (Constitución Provisoria para el Estado de Chile, 1818: título V, capítulo primero, artículo 2). ${ }^{7}$

El proceso de formación del derecho republicano en esta materia lo dejamos resumido en el punto 1 de este trabajo.

\section{Jurisprudencia de la Excelentísima Corte Suprema en aplicación de dicho principio}

Pese a la antigüedad de la vigencia imperativa de esta obligación jurisdiccional, nuestros jueces no siempre han sabido asimilar la trascendencia de este deber ministerial ni en virtud de la Ley de Organización y Atribuciones de los Tribunales (1875: artículo 9) -reiterado en el Código Orgánico de Tribunales de Chile (1943: artículo 10)- y ni siquiera por la fuerza vinculante de la norma constitucional actualmente vigente (Constitución Política de la República de Chile, 1980: artículo 76).

Para algunos jueces, resulta más cómodo eludir su obligación de abordar la cuestión que se les plantea con el pretexto inadmisible de no hallarse resuelta expresamente por la ley, que resolver materias que -a veces- son un simple ejercicio de lógica y, en todo caso, son materia esencial de su deber de impartir justicia (Resolución del $5 .^{\circ}$ Juzgado Civil de Valparaíso rol C-2528-2013, 2018; ${ }^{8}$ Resolución del 2. Juzgado Civil de Valparaí-

\footnotetext{
7. Título denominado «De la Autoridad Judicial».

8. Abordando una causa por expropiación, caratulada «Agrícola Los Canelos Limitada con Fisco de Chile» en 9 de abril de 2018, la titular del referido juzgado, proveyendo la designación de perito del fisco y luego de acogerla, resolvió a fojas 124: Notifíquese a fin que acepte el cargo, debiendo evacuar su informe pericial dentro de 20 días hábiles, contados desde que acepte dicho cargo y jure desempeñarlo fielmente. Como el tribunal no fijó plazo para dicha notificación, el expropiado lo solicitó para poder hacer cumplir
} 
so rol V-137-2016, 2017; Resolución del 2. Juzgado Civil de Valparaíso rol V-137-2016, 2018). ${ }^{9}$

En este estudio solo haremos referencia a los cinco fallos de nuestra Excelentísima Corte Suprema que en intervenciones recientes han hecho severa aplicación del principio en estudio.

\section{Sentencia de la Corte Suprema de Justicia rol 19.993-2016, 2016}

Emanada con fecha 4 de agosto de 2016, la tercera sala de la Excelentísima Corte Suprema, integrada por los ministros señor Sergio Muñoz G., señor Pedro Pierry A., señora Rosa Egnem S., y señora María Eugenia Sandoval G., y el abogado integrante señor Jorge Lagos G., conociéndose recurso de queja contra la Corte de Apelaciones de Santiago, en su considerando 9, estableció lo siguiente:

9. Que tales reflexiones ponen de manifiesto que la decisión de los sentenciadores de la Corte de Apelaciones de Santiago ha sido errada, pues la revocación del acto administrativo impugnado por el Banco del Estado de Chile no impide que el Tribunal de Contratación Pública se pronuncie con respecto a su legalidad, la que no fue declarada ni reconocida por el municipio reclamado al decidir ejercitar dicha facultad revocatoria, desde que, por el contrario, la decisión del ente edilicio se ha fundado exclusivamente en razones de mérito, conveniencia u oportunidad.

En estas condiciones y teniendo presente los deberes que sobre el citado tribunal recaen, particularmente el de inexcusabilidad prescrito en la Constitución Política de la República, forzoso es concluir que la sentencia de la Corte de Apelaciones de Santiago de treinta de marzo del año en curso acogió equivocadamente la reclamación prevista en el artículo 26 de la Ley 19.886, por cuanto ha quedado establecido que el Tribunal de Contratación Pública no solo se hallaba facultado sino que, aún más, estaba obligado a pronunciarse acerca de la legalidad del acto administrativo impugnado. En tales

lo resuelto, fundándose además en el Código de Procedimiento Civil de Chile (1902: artículo 238). Contestando el traslado, el fisco alegó que el Decreto Ley 2.186 de 1978 sobre Procedimiento Expropiatorio no contempla ningún plazo para ello. El tribunal negó lugar a lo solicitado. La afectada pidió reposición de lo resuelto fundándose además en cinco sentencias de la Corte Suprema y la juez titular. Después de considerar el traslado del fisco, rechazó el recurso de reposición en virtud de los mismos argumentos de la resolución recurrida, concediendo solo la apelación subsidiaria interpuesta.

9. En este proceso sobre consignación expropiatoria, caratulado «Fisco de Chile» por resolución de 3 de enero de 2017, el juez accedió a la solicitud del fisco de autorizarle a la toma de posesión material del bien expropiado, sin fijarle fecha para ello. Luego el fisco publicó en el Diario Oficial del 15 de febrero de 2018 su petición de toma de posesión material, advirtiendo que el expropiado tiene plazo de 5 días para recoger los frutos pendientes. El expropiado hizo uso de este derecho, solicitó plazo para su recolección y pidió al tribunal que fijara día y hora para la toma de posesión, ya que -a contar de esa fecha- corre un plazo fatal de caducidad del derecho a reclamar del monto de la indemnización. Contestando el traslado, el Fisco arguyó que: «No hay norma alguna que establezca que es su señoría quien deba fijar una fecha determinada para la realización de dicha diligencia». El tribunal, por resolución de 25 de junio de 2018, fundándose en «que, de acuerdo al Decreto de Ley 2.186, los trámites solicitados por el expropiado no están contemplados», dispuso «que se rechaza lo pedido por el expropiado, sin costas». 
circunstancias esta Corte, en uso de su facultad para obrar de oficio, debe enmendar el error en que se ha incurrido (Sentencia de la Corte Suprema de Justicia rol 19.9932016, 2016: considerando 9).

Y, en su parte resolutiva -después de haber desechado el recurso de queja por no ser procedente y actuando de oficio- dejó sin efecto la sentencia recurrida de la I. Corte de Apelaciones de Santiago y -en su lugar- desestimó el recurso de reclamación interpuesto contra el fallo del Tribunal de Contratación Pública.

\section{Sentencia de la Corte Suprema de Justicia rol 55.305-2016, 2017}

Fechada en 4 de abril de 2017, la tercera sala de la Excelentísima Corte Suprema, integrada por los ministros señor Sergio Muñoz G., señora Rosa Egnem S., señora María Eugenia Sandoval G., y señor Carlos Aránguiz Z., y el abogado integrante señor Juan Eduardo Figueroa V., conociendo de recurso de queja contra la I. Corte de Apelaciones de Santiago, en sus considerandos 7 y 15, razonó así:

Séptimo: Que, en primer lugar, se debe señalar que si bien los magistrados tienen un margen de interpretación de la ley, no es menos cierto que esta debe ejercerse dentro del marco de aquella. La relevancia de lo anterior radica en que los jueces, deben aplicar las normas que el ordenamiento jurídico contempla para resolver la controversia que ha sido puesta en su conocimiento, sin que puedan soslayar su existencia por atender a circunstancias fácticas que, a su juicio, podrían hacer estéril un pronunciamiento conforme a las normas específicas que regulan el caso concreto. Justamente, esta fue la conducta en la que incurren las juezas recurridas, toda vez que aquellas rechazan la reclamación interpuesta por haber entregado el órgano público, esto es, la Comisión de Energía Nuclear, la información relacionada con la lista de clientes que adquieren el litio concesionado a la quejosa, atendiendo a una conducta material, abstrayéndose de la cuestión jurídica que se debía resolver, amparando con ello una conducta que, de buena o mala fe, contraría el régimen de publicidad establecido en la Ley 20.285. Tal conducta, constituye por sí sola una falta o abuso grave, toda vez que aquellas han dejado de aplicar normas expresas que regulan la materia, so pretexto de estimar inútil la acción, puesto que a su juicio, cualquiera que sea la resolución, ya no pueden impedir la entrega de la información, razón por la que estiman que el arbitrio perdió oportunidad. Tal razonamiento es abusivo, puesto que, como se dijo, existiendo normas constitucionales y legales que regulan la materia, aquellos deben aplicarlas, sin atender a los efectos de su decisión, pues su labor es aplicar el derecho para resolver la controversia que fue puesta en su conocimiento (Sentencia de la Corte Suprema de Justicia rol 55.305-2016, 2017: considerando séptimo).

El mismo fundamento agrega más adelante que:

De este modo, se constata que las recurridas efectivamente incurrieron en falta o abuso grave, puesto que a pretexto de circunstancias fácticas ajenas al litigio se han abstenido de resolver la controversia sometida a su conocimiento, desconociendo no solo la aplicación de la normativa que regula el acceso a la información pública y las 
respectivas causales de reserva, vulnerando los artículo 8 de la Constitución Política de la República y 21 número 2 de la Ley de Transparencia, sino que además contravienen el mandato expreso contenido en el artículo 76 de la Carta Fundamental, que consagra el principio de inexcusabilidad, conforme al cual los jueces se encuentran obligados a resolver el conflicto de relevancia jurídica puesto en su conocimiento, a través de la aplicación de las normas jurídicas que regulan la materia, entregando así tutela judicial efectiva a quienes acuden a la judicatura (Sentencia de la Corte Suprema de Justicia rol 55.305-2016, 2017: considerando séptimo).

Y luego, el considerando 15 remata así:

Décimo quinto: Que, al haber obrado en la forma descrita en los fundamentos séptimo, octavo y noveno, las magistradas recurridas han actuado con abuso, puesto que omitieron la aplicación de texto normativo expreso que resolvía la controversia puesta en su conocimiento, faltando al principio de inexcusabilidad, al establecer que el reclamo de ilegalidad perdió oportunidad, fundadas en circunstancias ajenas a la normativa que regula la materia, según se analizó en el considerando séptimo. Asimismo, como se razonó en el fundamento octavo, validaron con grave falta, un examen realizado por el órgano público con respecto a la publicidad de la información, en circunstancias que este, conforme con lo establecido en el artículo 20 de la Ley 20.285, carece de atribuciones para tales efectos. Finalmente, de manera abusiva, omiten todo análisis de la causal de reserva invocada por el actor con respecto a la entrega del listado de sus clientes que adquieren el litio exportado, soslayando el análisis de las normas referidas en los fundamentos décimo a décimo cuarto, expresando una conclusión resolutiva carente de razonamientos jurídicos, constatándose así la efectividad de la denuncia esgrimida por la quejosa (Sentencia de la Corte Suprema de Justicia rol 55.305-2016, 2017: considerando décimo quinto).

En lo resolutivo, la Corte Suprema acogió el recurso de queja interpuesto en contra de la I. Corte de Santiago, dejando sin efecto su sentencia de 18 de agosto de 2016, motivo de la queja, y en su lugar dejó parcialmente sin efecto el amparo otorgado por el Consejo para la Transparencia en orden a dar a conocer el listado de adquirientes del litio exportado por S.Q.M., por su carácter reservado.

\section{Sentencia de la Corte Suprema de Justicia rol 832-2018, 2018}

Emitida el 18 de abril de 2018 por la primera sala de la Excelentísima Corte Suprema integrada por los ministros señor Guillermo Silva G., señoras Rosa María Maggi D., Rosa Egnem S., Gloria Ana Chevesich R., y el ministro suplente señor Rodrigo Biel M., consideró que en este caso, no obstante rechazar -por improcedente- el recurso de queja interpuesto en contra de la I. Corte de Santiago por la dictación de la sentencia materia del recurso, actuando de oficio resolvió la controversia fundándose en la infracción del principio de inexcusabilidad de la manera siguiente: «Sexto: (En lo pertinente) Sin perjuicio de lo resuelto, actuando esta Corte de oficio tiene presente lo que sigue» (Sentencia de la Corte Suprema de Justicia rol 832-2018, 2018: considerando sexto). 
A continuación, el fallo hace una prolija descripción del reclamo judicial dirigido en contra de una resolución de la Dirección Nacional del Trabajo, la cual denegó el recurso jerárquico esgrimido en contra del acto administrativo dictado por un órgano dependiente de ella.

En la audiencia verificada, ante el Juzgado del Trabajo, la Dirección Nacional interpuso una excepción de incompetencia absoluta del tribunal, fundándose en la norma del Código del Trabajo que prescribe que la decisión recurrida «solo será reclamable ante la Dirección Nacional del Trabajo» (Código del Trabajo de la República de Chile, 2003: artículo 360, inciso 11).

El Juzgado del Trabajo acogió dicha excepción, declarando su incompetencia; resolución que, una vez apelada, fue confirmada por la I. Corte de Apelaciones de Santiago.

El considerando sexto del fallo de la Excelentísima Corte Suprema luego de rechazar, en su segundo párrafo, el recurso de queja en sus numerales 3, 4 y 5, prosigue así:

3. Que es precisamente del tenor de la última frase recién transcrita que los jueces desprenden que, con la reclamación allí aludida no solo queda agotada la sede administrativa, sino que además las partes involucradas quedan privadas del derecho a acudir a la jurisdicción, y por ende, que los tribunales de justicia estarían impedidos de ejercer el cometido que les es propio, lo que traduce una clara vulneración de los principios básicos que gobiernan un estado de derecho.

4. Que, en efecto, y aun cuando se acude por los jueces al concepto de incompetencia absoluta, lo cierto es, que en estricto rigor se priva a los involucrados, en la especie al recurrente, de su derecho de acceder a la jurisdicción, desatendiendo con ello, entre otros, el principio de inexcusabilidad que nuestra Constitución Política de la República consagra en el artículo 76 , texto que reconoce exclusivamente a los tribunales establecidos en la ley la facultad de conocer las causas civiles y criminales, de resolverlas y hacer ejecutar lo juzgado. Añade el texto que: «...reclamada su intervención en forma legal y en negocios de su competencia, no podrán excusarse de ejercer su autoridad, ni aun por falta de ley que resuelva la contienda o asunto sometido a su decisión. Esta última prevención es reiterada en el artículo 10 del Código Orgánico de Tribunales. El recién referido principio de inexcusabilidad debe necesariamente ser vinculado a la noción de debido proceso y, específicamente con el ejercicio del derecho de acción, en cuanto prerrogativa de naturaleza fundamental que incluye no solo el acceso a la justicia sino también el amparo y tutela efectiva del derecho sustantivo que se reclama (así lo proponen los profesores Luis Guilherme Marinoni, Álvaro Pérez Ragone, y Raúl Núñez Ojeda, en su obra Fundamentos del proceso civil. Hacia una teoría de la adjudicación de Abeledo Perrot, 195-206). De esta manera, no es extremo reconducir este concepto a la idea de que la inexcusabilidad, además de expresarse como una prohibición al juez de eludir la decisión de la cuestión que se somete a su conocimiento, también configura la prohibición de apartar del control jurisdiccional cualquier asunto que, cumpliendo las exigencias del artículo 76 de la Constitución Política de la República, deba caer bajo el amparo del órgano jurisdiccional correspondiente, conclusión que se ve claramente reafirmada y complementada con el tenor del inciso segundo del artículo 38 de la Carta Magna, al señalar que «cualquier persona que sea 
lesionada en sus derechos por la administración del Estado, de sus organismos o de las municipalidades, podrá reclamar ante los tribunales que determine la ley, sin perjuicio de la responsabilidad que pudiere afectar al funcionario que hubiere causado el daño». Ninguna duda cabe que en la especie se está en presencia de un conflicto de relevancia jurídica que genera y hace operativo el poder-deber entregado a los tribunales para conocer de él y de resolverlo por la vía del instrumento denominado proceso, y con efecto de cosa juzgada.

5. Que en concordancia con lo anterior, no es posible soslayar que el ordenamiento jurídico, partiendo por la Carta Magna, otorga al ciudadano la garantía básica de un justo y racional procedimiento para ser sustanciado y resuelto ante un juez imparcial, que debe sujetarse a la ritualidad que la ley contempla para llevar adelante el proceso, y, lo que es de suyo relevante, quedando aquel también sujeto al sistema de ponderación de las pruebas que ha predeterminado el legislador (Sentencia de la Corte Suprema de Justicia rol 832-2018, 2018: considerando sexto, numerales 3 a 5).

Más adelante, en el numeral 12 del mismo considerando sexto, la Excelentísima Corte Suprema concluye así:

12. Que en las condiciones ya señaladas, resulta claro que al acoger la excepción de incompetencia absoluta interpuesta por la Dirección del Trabajo en la audiencia del 5 de octubre de 2017 , se incurrió en un error que privó a la parte reclamante de la adecuada sustanciación del procedimiento al que se había dado curso en la causa Rit I-405-2017, del Primer Juzgado de Letras del Trabajo con arreglo a lo previsto por el artículo 504 del Código del ramo, yerro que hizo suyo la Corte de Apelaciones al confirmar la decisión en comento, anomalía la indicada, que esta Corte debe enmendar en uso de sus atribuciones (Sentencia de la Corte Suprema de Justicia rol 832-2018, 2018: considerando sexto, numeral 12).

Finalmente, en la parte resolutiva, el fallo de la Excelentísima Corte Suprema decidió que:

Por estos fundamentos, y actuando de oficio esta Corte, se deja sin efecto la resolución de tres de enero pasado, dictada por la Corte de Apelaciones de Santiago, en cuanto confirmó la de primer grado que acogió la excepción de incompetencia deducida por la Dirección del Trabajo y en su lugar se decide que se revoca tal decisión, y en consecuencia se declara que la excepción de incompetencia absoluta queda desestimada, debiendo el tribunal a quo disponer la prosecución del procedimiento por el juez no inhabilitado que corresponda (Sentencia de la Corte Suprema de Justicia rol 832-2018, 2018: parte resolutiva).

\section{Sentencia de la Corte Suprema de Justicia rol 7342-2018, 2018}

Con fecha 25 de julio de 2018, la cuarta sala de la Excelentísima Corte Suprema, integrada por los ministros señora Rosa Egnem S., señor Ricardo Blanco H., señora Gloria Ana Chevesich R., y los abogados integrantes señora Leonor Etcheberry C., y señor 
Iñigo De la Maza G., pronunciándose sobre un recurso de queja interpuesto en contra de la décima sala de la Corte de Apelaciones de Santiago, la que confirmó la sentencia dictada por el Juez del Trabajo, quien declaró su incompetencia absoluta para conocer de la reclamación deducida en contra del Director Nacional del Trabajo, fundándose en el Código del Trabajo de la República de Chile (2003: artículo 360, inciso 11), que prescribe que la resolución de la Dirección Regional del Trabajo «solo será reclamable ante la Dirección Nacional del Trabajo».

A esta materia nos referimos en el párrafo 4 de la sentencia precedente; y la cuarta sala de la Excelentísima Corte Suprema reproduce los fundamentos básicos del fallo referido de la primera sala, por lo que solo haremos referencia a las consideraciones agregadas a este fallo.

En su considerando sexto, numeral 10, la cuarta sala precisa:

10. Que es en el contexto de lo hasta aquí descrito y en concordancia con los principios y normas supra legales y aquellas legales citadas, que solo cabe concluir que el artículo 360 en su inciso undécimo no pudo ser interpretado sino conforme a su tenor y prístino sentido, lo que significa que no es posible atribuirle otro alcance que el de demarcar el agotamiento de la vía administrativa, pero en modo alguno impedir o privar al afectado con la decisión de la Dirección Nacional del Trabajo, de acudir a la sede jurisdiccional. Lo expresado guarda coherencia con lo dispuesto por el artículo 19 número 26 de la Constitución Política de la República, y con el ordenamiento jurídico internacional que reconoce el derecho a recurrir ante el juez correspondiente para los efectos de resolver las controversias surgidas en el ámbito de la libertad sindical, contexto en el cual se inserta la problemática que aquí se trata. Así lo reconoce, por ejemplo, el Comité de Libertad Sindical del Consejo de Administración de la Organización Internacional del Trabajo, que al pronunciarse a propósito del derecho de huelga, y específicamente, acerca de sus restricciones, como las referidas a los servicios mínimos, en específico, con respecto a las situaciones y condiciones en que puede imponerse tal calificación, señala que «un pronunciamiento definitivo y con completos elementos de apreciación sobre si el nivel de servicios mínimos fue o no el indispensable solo puede realizarse por la autoridad judicial, toda vez que supone en particular un conocimiento en profundidad de la estructura y funcionamiento de las empresas y establecimientos concernidos y del impacto efectivo que tuvieron las acciones de huelga (en "La libertad sindical - Recopilación de decisiones y principios del Comité de Libertad Sindical del Consejo de Administración de la OIT". Quinta edición revisada, 2006, p. 133, disponible en el sitio web de dicho organismo)» (Sentencia de la Corte Suprema de Justicia rol 7342-2018, 2018: considerando sexto, numeral 10).

Cabe señalar que en el encabezamiento del mismo considerando 6, la Excelentísima Corte Suprema rechazó el recurso de queja, materia de este proceso, y prosiguió actuando de oficio. Por esto, en la parte resolutiva el fallo concluyó así:

Por estos fundamentos, y actuando de oficio esta Corte, se deja sin efecto la resolución de trece de abril último, dictada por la Corte de Apelaciones de Santiago, en cuanto confirmó la de primer grado que declaró la incompetencia del tribunal para 
conocer de la reclamación deducida, y, en su lugar, se decide que se revoca tal decisión, y en consecuencia, se declara que el tribunal a quo deberá disponer la prosecución del procedimiento por el juez no inhabilitado que corresponda (Sentencia de la Corte Suprema de Justicia rol 7342-2018, 2018: parte resolutiva).

\section{Sentencia de la Corte Suprema de Justicia rol 2573-2019, 2019}

En fecha aún más reciente, el 6 de febrero de 2019, la tercera sala de la Excelentísima Corte Suprema integrada por los ministros señor Sergio Muñoz G., señor Ricardo Blanco H. y señora Angela Vivanco M., el ministro suplente señor Rodrigo Biel M. y el abogado integrante señor Antonio Barra R., aludió a su «deber de inexcusabilidad» frente a una resolución del Excelentísimo Tribunal Constitucional que -en un requerimiento de inaplicabilidad por inconstitucionalidad- habría ordenado la suspensión de un procedimiento, el que no incluía el proceso en que dicha suspensión aparente había sido solicitada.

Luego de aclarar en el considerando tercero que la suspensión del procedimiento se refiere a un proceso distinto al que es materia de esta sentencia, la Excelentísima Corte Suprema declara lo siguiente:

Cuarto: Que, como se lee, la suspensión del procedimiento no puede entenderse extensiva al conocimiento y resolución del presente recurso de hecho, pues sus efectos han quedado expresamente delimitados por la petición formulada por las propias requirentes, restringiéndolo a un único y singular ingreso: El rol 254-2019 de esta Corte Suprema; conclusión que, por lo demás, se ve reafirmada por la excepcionalidad de dicha medida suspensiva, y por el deber de inexcusabilidad que la Constitución Política de la República y la ley imponen a esta magistratura (Sentencia de la Corte Suprema de Justicia rol 2573-2019, 2019: considerando cuarto).

Finalmente, en la parte resolutiva, acoge el recurso de hecho interpuesto por la Corporación Nacional de Consumidores y Usuarios de Chile en contra de la resolución del Tribunal de Defensa de la Libre Competencia rol C-275-2014 de 2019, que se deja sin efecto y niega lugar al recurso de apelación subsidiario interpuesto por Entel S.A. en los autos de dicho tribunal especial.

Queda en claro la estricta sujeción de la Corte Suprema al principio fundamental en estudio, en virtud del cual ha sabido rectificar la actuación indebida de tribunales ordinarios y especiales de jerarquía inferior.

\section{Consecuencias de la infracción de este deber jurisdiccional}

El carácter fundamental del deber de inexcusabilidad se traduce, en definitiva, en el deber de todo tribunal de hacer justicia. Esta corre el riesgo de diferirse y hasta denegarse por eludir el juez su obligación esencial.

Piénsese en las funestas consecuencias jurídicas que habría traído -en los cinco 
casos relatados en el capítulo precedente- la falta de intervención oportuna de la Excelentísima Corte Suprema en todos esos procesos, en algunos de los cuales -rechazando la vía de la queja escogida por el recurrente- actuó de oficio, cargando sobre ella el deber de inexcusabilidad de todo tribunal de justicia que había quedado desprovisto de resguardo y resolvió acertadamente la irregularidad procesal cometida por el sentenciador recurrido y, en otros, señaló claramente el camino a retomar con sujeción al principio de inexcusabilidad.

Ahora bien, cuando la actitud excusatoria del juez se traduce en su abstención de resolver un asunto que dilata indebidamente el curso del proceso -como en los ejemplos de resoluciones de primera instancia citadas- se produce un retardo injustificado de la justicia. Y, como se sabe, «justicia tardía no es justicia».

Cuando la actuación del juez consiste en eludir la legislación aplicable en una materia de su competencia, dando lugar a otra legislación eventual en la que carece de competencia, su actitud no solo infringe las reglas de la competencia, sino que contraviene abiertamente su deber de inexcusabilidad y su obligación de resolver una materia legislada en la que ha sido requerido y en la cual es claramente competente (Resolución del 5. Juzgado Civil de Valparaíso rol C-2893-2016, 2018; Sentencia de la Corte de Apelaciones de Valparaíso rol Civil-356-2018, 2018). ${ }^{10}$

10. Con fecha 1 de febrero de 2018, la juez titular del 5. Juzgado Civil de Valparaíso, resolviendo una incidencia de derogación legal en causa caratulada «Fisco de Chile con Agrovivo S.A», dictó la siguiente resolución: «Vistos y teniendo presente: i) Que, con fecha 17 de enero de 2018, comparece (N.N.) en representación de Agrovivo S.A., interponiendo incidente de previo y especial pronunciamiento, a fin que se declare la derogación de la expresión "el expropiante", contenida en el artículo 12 del Decreto de Ley 2.186, esgrimiendo para ello, su inconstitucionalidad (sic.), en virtud de los fundamentos que expresa. ii) Que, el Fisco de Chile evacuando el traslado, el 25 de enero de 2018, solicita el rechazo del incidente, toda vez que sus fundamentos son los de una acción de inaplicabilidad que no debe deducirse en este Tribunal. iii) Que, el artículo 93 número 6 de la Constitución Política de la Republica, señala que la inaplicabilidad de un precepto legal que resulte contrario a la Carta Fundamental, que se suscite en una gestión ante un tribunal ordinario, es de competencia del Tribunal Constitucional. iv) Que, de acuerdo al mérito de los antecedentes y teniendo en especial consideración, la norma Constitucional citada, aparece de manifiesto que este tribunal no es competente para pronunciarse respecto a lo solicitado (sic.) por Agrovivo S.A., en virtud de lo cual se resuelve que: Se rechaza, incidente de previo y especial pronunciamiento deducido a lo principal de la presentación de 17 de enero de 2018, con costas». Solicitada su reposición, haciendo ver que la incidencia versaba sobre la derogación de una norma legal, y que la cuestión de inaplicabilidad había sido introducida por el fisco de Chile, la misma magistrada insistió en que se trataba de una inconstitucionalidad y rechazó la reposición, concediendo la apelación subsidiaria. La segunda sala de la I. Corte de Valparaíso, el 26 de junio de 2018, resolviendo el incidente cuya suma dice: «Como incidente de previo y especial pronunciamiento opone la derogación de la disposición contenida en el artículo 12 del Decreto de Ley 2.186 que sirve de fundamento a la demanda, etcétera», dispuso lo siguiente: «II. En cuanto al incidente de lo principal de la presentación de 17 de enero de 2018. Atendido el mérito de los antecedentes, los fundamentos de la resolución recurrida y entendiendo que en la especie lo que se reclama es la inconstitucionalidad (sic.) de un precepto legal, se considera al efecto, que el control de constitucionalidad concreto que la Carta Fundamental entrega en el numeral sexto del artículo 93 de su texto reformado el año 2005, corresponde en forma exclusiva y excluyente al Tribunal Constitucional, se confirma la resolución de uno 


\section{Consecuencias procesales de su infracción}

Estas consecuencias van a depender de la naturaleza de la resolución que contenga la infracción al deber de inexcusabilidad y, por ende, de los recursos procesales que se admitan en su contra (Código de Procedimiento Civil de Chile, 1902: artículo 158). ${ }^{1{ }^{1}}$

Así, si se trata de un auto o de un decreto, estos son susceptibles del recurso de reposición conforme al Código de Procedimiento Civil de Chile (1902: artículo 181). Y aun cuando -por la regla general del mismo cuerpo legal (Código de Procedimiento Civil de Chile, 1902: artículo 188) - ellos no son apelables, excepcionalmente lo son cuando la resolución impugnada altera la substanciación regular del juicio o cuando recae sobre trámites que no están expresamente ordenados por la ley, según lo autoriza la misma disposición. Es el caso de los ejemplos de resoluciones en procedimientos civiles citados al inicio del capítulo anterior.

De acuerdo con el Código de Procedimiento Civil de Chile (1902: artículo 766), si la resolución que afecta el deber de inexcusabilidad está contenida en una sentencia definitiva, puede ser susceptible del recurso de casación en la forma siempre que dicho deber recaiga en alguna de las causales contempladas en dicho Código (Código de Procedimiento Civil de Chile, 1902: artículo 768), especialmente en los motivos 5 y 9; y siempre que se dé cumplimiento a los demás requisitos de procedencia que exige la ley procesal.

También procederá la casación en la forma contra las sentencias interlocutorias cuando ellas pongan término al juicio o hagan imposible su continuación, de acuerdo con el mismo Código de Procedimiento Civil de Chile (1902: artículo 766).

El recurso de casación en el fondo tiene lugar, conforme al Código de Procedimiento Civil de Chile (1902: artículo 767), en contra de las sentencias definitivas inapelables y en contra de las interlocutorias inapelables cuando ellas ponen término al juicio o hacen imposible su continuación. Estas sentencias deben haberse pronunciado con infracción de ley -con mayor razón, el recurso es procedente si ellas infringen la Constitución- y siempre que dicha infracción haya influido substancialmente en lo dispositivo de la sentencia.

\section{Consecuencias disciplinarias de la infracción del deber de inexcusabilidad}

Conforme a nuestra Carta Fundamental (Constitución Política de la República de Chile, 1980: artículo 82), la Excelentísima Corte Suprema tiene la superintendencia directiva (jerárquica), correccional (disciplinaria) y económica (administrativa) de todos los tribunales ordinarios de la República.

de febrero de dos mil dieciocho, escrita a fojas 19 de esta carpeta judicial». Aquí no solo ambos tribunales eludieron pronunciarse sobre la incidencia de derogación en la que ambos eran competentes, sino que, además, declararon la competencia del Tribunal Constitucional, que no la tiene para declarar la derogación de una norma legal (Constitución Política de la República de Chile, 1980: artículo 93), siendo esta de la competencia propia de la justicia ordinaria.

11. La definición de las distintas clases de resoluciones judiciales está contenida en el artículo citado. 
Los tribunales superiores, que incluyen a las Cortes de Apelaciones, en uso de sus facultades disciplinarias, solo podrán invalidar resoluciones jurisdiccionales en los casos y forma que establezca la ley orgánica constitucional respectiva.

Por su parte, el Código Orgánico de Tribunales de Chile (1943: título XVI) trata «De la jurisdicción disciplinaria» y de otras materias afines.

Interesa destacar la expresión «correccional» que utiliza la Constitución al referirse a esta jurisdicción. E interesa hacerlo porque la razón y la finalidad principal de este ejercicio del poder consiste en corregir los errores, las faltas o los abusos que puedan cometer los tribunales inferiores al titular de esta potestad en el ejercicio de su función jurisdiccional.

La sanción que pueda merecer quien dictó la resolución errónea o reprobable constituye una consecuencia eventual -no siempre procedente- y secundaria del objetivo principal.

El Código Orgánico de Tribunales de Chile prescribe que:

El recurso de queja tiene por exclusiva finalidad corregir las faltas o abusos graves cometidos en la dictación de resoluciones de carácter jurisdiccional. Solo procederá cuando la falta $o$ abuso se cometa en sentencia interlocutoria que ponga fin al juicio o haga imposible su continuación o definitiva, y que no sean susceptibles de recurso alguno, ordinario o extraordinario, sin perjuicio de la atribución de la Corte Suprema para actuar de oficio en ejercicio de sus facultades disciplinarias (Código Orgánico de Tribunales de Chile, 1943: artículo 545).

\section{Consecuencias penales de la infracción de este deber}

Si un juez incurre en la infracción de este deber fundamental, puede ser sancionado por dos tipos penales de prevaricación según el caso, que el Código Penal contempla bajo esta denominación (Código Penal de la República de Chile, 1874: libro II, título V, párrafo IV).

Sobre esto, el profesor Edgardo López Pescio señala que:

Si los jueces no cumplen este principio o violan las normas legales en las cuales está contenido, pueden incurrir en responsabilidad penal, ya que la ley establece que los jueces serán penados «cuando maliciosamente nieguen o retarden la administración de justicia y el auxilio o protección que legalmente se les pida», de acuerdo con el artículo 224 número 3 del Código Penal o cuando «negaren o retardaren la administración de justicia y el auxilio o protección que legalmente se les pida», como lo dispone el artículo 225 número 3 del citado Código Penal (López Pescio, 1987: 260-261).

En este segundo caso deben haber obrado con negligencia o ignorancia inexcusables.

\section{Conclusión}

La inexcusabilidad resolutiva es un principio rector de la función jurisdiccional. Consiste en la obligación de todo tribunal de resolver la contienda o asunto sometido le- 
galmente a su decisión y que esté dentro de competencia, debiendo hacerlo conforme a las normas que lo regulan y, en su ausencia, de acuerdo con las demás fuentes del derecho disponibles. Este principio jurídico está positivado en el Código Orgánico de Tribunales de Chile (1943: artículo 10) y fue elevado al rango de norma constitucional al ser incluido en la actual Carta Fundamental de Chile (1980: artículo 76).

$\mathrm{Su}$ trascendencia es tan evidente que, por hallarse ligado a la realización de la justicia, forma parte de la seguridad jurídica de la nación y de la confianza pública en la vigencia de aquella.

Este deber, así como las prerrogativas de la función jurisdiccional, tienen fundamento en la soberanía del Estado.

La inexcusabilidad resolutiva es un deber ineludible de todo tribunal de justicia que se hace exigible ante cualquier requerimiento judicial que se le haga en conformidad a la ley y en materias de su competencia. Aunque pareciera ser que el deber de inexcusabilidad resolutiva nació a raíz del proceso de codificación que se inicia a comienzos del siglo XIX, lo cierto es que su origen se remonta, al menos, a la temprana Edad Media, hallándose claramente establecido en el Libro de los jueces del año 654 de nuestra era, manteniéndose vigente en toda la historia del Imperio español y de sus colonias. En el caso de Chile, se advierte que, a veces, algunos tribunales especiales como son los que se mencionan en la jurisprudencia de la Excelentísima Corte Suprema, y también algunos tribunales ordinarios de justicia, como los que se señalan al comienzo del acápite que trata esta materia, incumplen el deber de inexcusabilidad.

Finalmente, las consecuencias de la infracción del principio positivado de inexcusabilidad resolutiva pueden ser resueltas, ya sea mediante el ejercicio de los recursos procesales ordinarios -según sea la naturaleza de la resolución que la contiene- ya sea mediante el ejercicio del recurso extraordinario de la queja, como la acreditan algunos de los fallos de la Excelentísima Corte Suprema descritos en la sección a ello dedicada; o bien, haciendo efectiva la responsabilidad penal del o de los jueces que incurren en esas infracciones.

El día en que todos los jueces -especialmente los que actúan en la primera instancia-tomen conciencia del tremendo poder que tienen en sus manos y -sobre todo- de la decisiva contribución que su buen ejercicio haría al reinado de la justicia y a la paz social de nuestros pueblos, habremos dado un enorme salto cualitativo, superando la denegación de justicia, las dilaciones injustificadas y la desesperación que, a veces, provoca en sus víctimas la inobservancia del deber de inexcusabilidad.

\section{Referencias}

Ávila Martel, Alamiro de (1995). Curso de Historia del Derecho. Tomo I. Santiago: Jurídica de Chile.

Corral Talciani, Hernán (1987). De la ignorancia de la ley. El principio de inexcusabilidad. Santiago: Jurídica de Chile. 
Fernández GonzÁLEZ, Miguel Ángel (2014). «El principio constitucional de inexcusabilidad». Revista de Derecho Público, 80: 41-52. DOI: 10.5354/0719-5249.2014.33319.

Figueroa Quinteros, María Angélica (1996). «Algunos antecedentes históricos sobre los principios de inexcusabilidad y legalidad», Revista de Estudios Histórico-Jurídicos, 18: 187-196. Disponible en https://bit.ly/2ZayxPq.

GuAsP, Jaime (1961). Derecho procesal civil. Madrid: Instituto de Estudios Políticos.

LóPez Pescio, Edgardo (1987). Nociones generals de derecho procesal. 1. ${ }^{a}$ parte. Valparaíso: EDEVAL.

Martínez Benavides, Patricio (2012). «El principio de inexcusabilidad y el derecho de acción desde la perspectiva del Estado constitucional». Revista Chilena de Derecho, 39 (1): 113-147. DOI: 10.4067/So718-34372012000100006.

Pereira Anabalón, Hugo (1993). Curso de derecho procesal. Tomo I. Santiago: Jurídica Conosur.

Ríos ÁlvAREZ, Lautaro (2015). «El principio de congruencia en la doctrina y en la jurisprudencia de la Excelentísima Corte Suprema». En Asociación Chilena de Derecho Constitucional (editor), Poder Judicial. Libro Homenaje al profesor Paulino Varas Alfonso (pp. 249-272). Santiago: Jurídica de Chile.

Topasio Ferreti, Aldo (1983). «Fundamentos históricos del Principio de Inexcusabilidad del Juez en el devenir jurídico hispánico y chileno». Revista Chilena de Historia del Derecho, 9: 155-164. DOI: 10.5354/0719-5451.2012.25688.

\section{Sobre el autor}

Lautaro Ríos Álvarez es exprofesor de Teoría Política y Derecho Constitucional de la Facultad de Derecho de la Universidad de Valparaíso y profesor emérito de dicha universidad; magíster en Derecho Administrativo por la Universidad de Chile; doctor en Derecho por la Universidad Complutense de Madrid; miembro y exvicepresidente de la Asociación Chilena de Derecho Constitucional; y miembro correspondiente en Chile de las Asociaciones Argentina y Peruana de Derecho Constitucional. Su correo electrónico es lautarorios@estudiorios.cl. 